\title{
DSC STUDY OF PRECIPITATION IN AN AL-MG-MN ALLOY MICROALLOYED WITH CU
}

\author{
M.J. Starink, A. Dion \\ Materials Research Group, School of Engineering Sciences, University of Southampton, \\ Southampton S017 1BJ, UK
}

Keywords: $\quad$ DSC, thermal analysis, precipitation, 3xxx alloy, S phase

\begin{abstract}
Power compensation DSC has been employed to detect and analyse precipitation reactions in an Al1.3Mg-0.4Mn and an Al-1.3Mg-0.4Mn-0.07Cu alloy in which very small amounts of precipitate, less than 0.3 at\%, are expected to form. Due to the very small heat effects, baseline instability and drift significantly interfere with the measurements. After repeated experiments and careful baseline correction it is demonstrated that in the Cu containing alloy, ageing at $170^{\circ} \mathrm{C}$ causes the appearance of two endothermic effects: for 2 days ageing a small dissolution effect appears at about $230^{\circ} \mathrm{C}$, whilst for 7 and 21 days ageing a dissolution effect peaking appears at about $300^{\circ} \mathrm{C}$. The temperature range of the latter is consistent with $\mathrm{S}$ phase dissolution.
\end{abstract}

\section{Introduction}

Differential scanning calorimetry (DSC) and isothermal calorimetry are extensively used for the study of precipitation in heat treatable Al based alloys [1]. Studies are conducted on alloys in which the amount of alloying elements that precipitate is typically in the range of 1 to 10 atomic percent. For instance, in commercial Al-Cu-Mg alloys (e.g. AA2024: Al-1.6at\%Cu-1at\%Mg) the amount of $\mathrm{Cu}$ and $\mathrm{Mg}$ atoms that precipitate to form $\mathrm{S}$ phase is about 2at\% [2,3], in an Al-1at\%Si alloy the amount of Si that precipitates is about 1at\% [4], in commercial Al-Zn-Mg-Cu based alloys the amount of precipitates is in the order of 4 to $7 \mathrm{at} \%[5,6]$ (but these precipitates will contain some $\mathrm{Al})$, in $\mathrm{Al}-\mathrm{Li}-\mathrm{Cu}-\mathrm{Mg}$ alloys the amount of $\mathrm{Li}$ that precipitates to form $\delta^{\prime}$ phase $\left(\mathrm{Al}_{3} \mathrm{Li}\right)$ is about 2 to 3 at\% $[7,8]$ and in $\mathrm{Al}-16 \mathrm{at} \% \mathrm{Mg}$ the amount of $\mathrm{Mg}$ atoms that precipitates to form $\beta "\left(\mathrm{Al}_{3} \mathrm{Mg}\right)$ phase is about 6at\% [9]. The $\mathrm{Al}$ alloys with the smallest amount of precipitation which have been studied by calorimetry are probably the $\mathrm{Al}-4.7 \mathrm{at} \% \mathrm{Mg}-0.25 \mathrm{at} \% \mathrm{Cu}-0.14 \mathrm{at} \% \mathrm{Si}$ alloy, in which about $0.5 \mathrm{at} \%$ of $\mathrm{Cu}$ and $\mathrm{Mg}$ are expected to combine to form $\mathrm{S}$ phase $\left(\mathrm{Al}_{2} \mathrm{CuMg}\right)[10,11]$ and the $\mathrm{Al}-0.5 \mathrm{at} \% \mathrm{Mn}$ $0.3 a t \% F e$ based AA3003 alloy in which most of the Mn and Fe is thought to form intermetallic Al, $\mathrm{Mn}$ and Fe containing precipitates [12]. As far as we are aware no attempts to detect or analyse precipitation with calorimetry have been reported for metallic alloys in which the total amount of precipitating alloying elements is less than $0.5 \mathrm{at} \%$.

The present paper reports work on a very dilute precipitation system: an Al-1.3at\%Mg-0.4at\%Mn alloy microalloyed with up to $0.07 \mathrm{at} \% \mathrm{Cu}$. If $\mathrm{S}$ phase $\left(\mathrm{Al}_{2} \mathrm{CuMg}\right)$ forms in this alloy, the maximum 
volume fraction is determined mostly by the amount of $\mathrm{Cu}$ in the alloy. (The rod or lath shaped precipitates in Al-Cu-Mg alloys, which have often been indicated by S', are a slightly strained semicoherent version of the (incoherent) $S$ phase. In recent works [7,13,14] several researchers have thus decided to discontinue the use of the indication S'. This is thought to be appropriate, and for the present paper we will not use the term S' phase, and instead indicate all precipitates with the same structure as $\mathrm{S}$ phase.) The solubility of $\mathrm{Cu}$ in the $\mathrm{Al}$ rich phase at $170^{\circ} \mathrm{C}$ in the presence of $1 \mathrm{at} \% \mathrm{Mg}$ is lower than $0.001 \mathrm{at} \%$ (see discussion section) and hence is nearly negligible. Thus we can assume that all $\mathrm{Cu}$ is available for precipitation. The amount of $\mathrm{S}$ phase should be about $4 \times 0.07 \mathrm{at} \%$. Detecting this small amount of $\mathrm{S}$ phase is challenging because heat effects will be very small, causing equipment noise and baseline instabilities to interfere with the measurement. But analysis of these alloys is important because the small amounts of $\mathrm{S}$ phase can cause a small but significant strengthening and thus the present paper sets out to analyse the formation of precipitates in the Al1.3at\%Mg-0.4at\%Mn alloy microalloyed with $0.07 \mathrm{at} \% \mathrm{Cu}$.

The Al-1.3at\%Mg-0.4at\%Mn alloy is generally indicated as AA3104, and these alloys based on AlMg-Mn are generally considered to be non-heat treatable alloys. Currently, these alloys are widely used in packaging applications. Work hardening and solid solution strengthening are two effective ways to improve their strength, but it has been realised that precipitation induced by small additions of $\mathrm{Cu}$ can play a role in work hardening and cause precipitation hardening [15,16,17]. Another reason for the interest in these type of alloys is the new trend in the automobile industry to exploit new $\mathrm{Al}$ alloys as car body panels to reduce weight and thus reduce fuel consumption [18]. Al-MgMn alloys of the 5XXX series (especially AA5182, AA5052) with Cu additions are very promising candidates for that application due to their excellent formability and good strength, moreover the precipitation induced by small $\mathrm{Cu}$ additions may also influence corrosion [19] and reduce recovery [20]. Therefore, it is important to understand the precipitation in these alloy systems and to quantitatively elucidate their mechanisms.

\section{Experimental.}

Two alloys are investigated, an $\mathrm{Al}-1.3 \mathrm{at} \% \mathrm{Mg}-0.4 \mathrm{at} \% \mathrm{Mn}$ alloy and an $\mathrm{Al}-1.3 \mathrm{at} \% \mathrm{Mg}-0.4 \mathrm{at} \% \mathrm{Mn}-$ $0.07 \mathrm{at} \% \mathrm{Cu}$ alloy. The alloys were supplied by Alcan International, Banbury Labs, UK in the form of sheets. The sheet was produced through casting, homogenising, hot rolling in several passes, solution treatment to dissolve $\mathrm{Cu}, \mathrm{Mg}$ and most of the $\mathrm{Mn}$ and subsequent cold deformation through cold rolling or stretching. The alloys were produced with varying levels of cold deformation. Samples with 2 and 5\% cold deformation were deformed through stretching, whilst the 10\% cold deformed samples were deformed by cold rolling. The samples were stored at room temperature for several weeks, and subsequently aged at $170^{\circ} \mathrm{C}$ for 2,7 or 21 days.

Table 1: Composition of the two alloys studied.

\begin{tabular}{|l|r|r|c|c|c|c|}
\hline Alloy & Si (\%) & Fe (\%) & Cu (\%) & Mn (\%) & Mg (\%) & Zn (\%) \\
\hline Al-1.3Mg-0.4Mn & 0.19 & 0.19 & 0.07 & 0.44 & 1.34 & 0.01 \\
Al-1.3Mg-0.4Mn-0.07Cu & 0.19 & 0.19 & 0.00 & 0.44 & 1.34 & 0.00 \\
\hline
\end{tabular}


All DSC experiments were conducted in a Perkin Elmer Pyris 1 Calorimeter, which is a power compensation DSC [1,21]. Nitrogen was used as both a purge and protective gas. Prior to a day of performing DSC runs, a cleaning run was done to improve the repeatability. In analysing linear heating experiments the baseline of the DSC needs to be carefully considered, as baselines will generally be temperature and time dependent [22], and a comparison of baselines measured confirmed that this was also the case for our instrument. Therefore the following procedure was followed. Before testing samples, a baseline run with empty sample holders was performed. This baseline run is later used to subtract from the experimental results to determine the baseline correction. This will thus provide the enthalpy changes related to the sample, taking account of a correction for (some of the) the imperfections of the DSC machine. A second baseline run was performed in the course of the day in such a manner that always a baseline run is available that was performed within 3 hours of a DSC experiment on an actual sample. Occasionally a third baseline run was performed. For all alloy/ageing combinations two samples were tested. With at least two baselines available for each sample, at least 4 corrected experimental curves are available.

\section{Results.}

Fig. 1 shows an example of the thermograms obtained after correction of the DSC run on the sample with a DSC run performed with empty sample holders. The sample studied here is the Al1.3at\%Mg-0.4at\%Mn-0.07at\%Cu 10\% deformation sample aged for 21 days at $170^{\circ} \mathrm{C}$. These curves are dominated by continuous slope indicating an ever increasing endothermic effect. Superimposed on this there are common features in the form of endothermic effects around 300 and $470^{\circ} \mathrm{C}$. The continuous slope is thought to be due mostly to the difference in heat capacity of sample and reference, and also imperfections in the DSC measurement play a role as for this type of DSC the baseline (run with empty holders) varies with time [22]. The heat capacity of aluminium is in good approximation a linear function of the temperature and hence, in a first order correction we may correct the curves by subtracting a linear function, provided we can identify section(s) of the curve in which no reactions occur. For the present alloys we can expect that no significant reactions occur up to $200^{\circ} \mathrm{C}$, and hence we will apply the linear correction by fitting a linear function to the section of curves between 100 and $200^{\circ} \mathrm{C}$. DSC thermograms obtained after this linear correction are presented in Fig. 2, for the same alloy / ageing combinations as shown in Fig. 1. The latter figure shows that even though the samples and the experiments were nominally identical, there are differences between the 4 measurements of the heat evolution from the sample, and these differences increase as the temperature increases over $200^{\circ} \mathrm{C}$. Thus parts of the measurements are associated with a substantial level of uncertainty. Nevertheless, some effects are determined quite consistently. Firstly, all thermograms show a linear part up to about $200^{\circ} \mathrm{C}$, which is interpreted as indicating a temperature range where no reactions take place. Secondly, a distinct endothermic effect is present between about 210 and $350^{\circ} \mathrm{C}$, with a peak at $300^{\circ} \mathrm{C}$. Thirdly, an endothermic effect with a peak at $460^{\circ} \mathrm{C}$ is observed. 


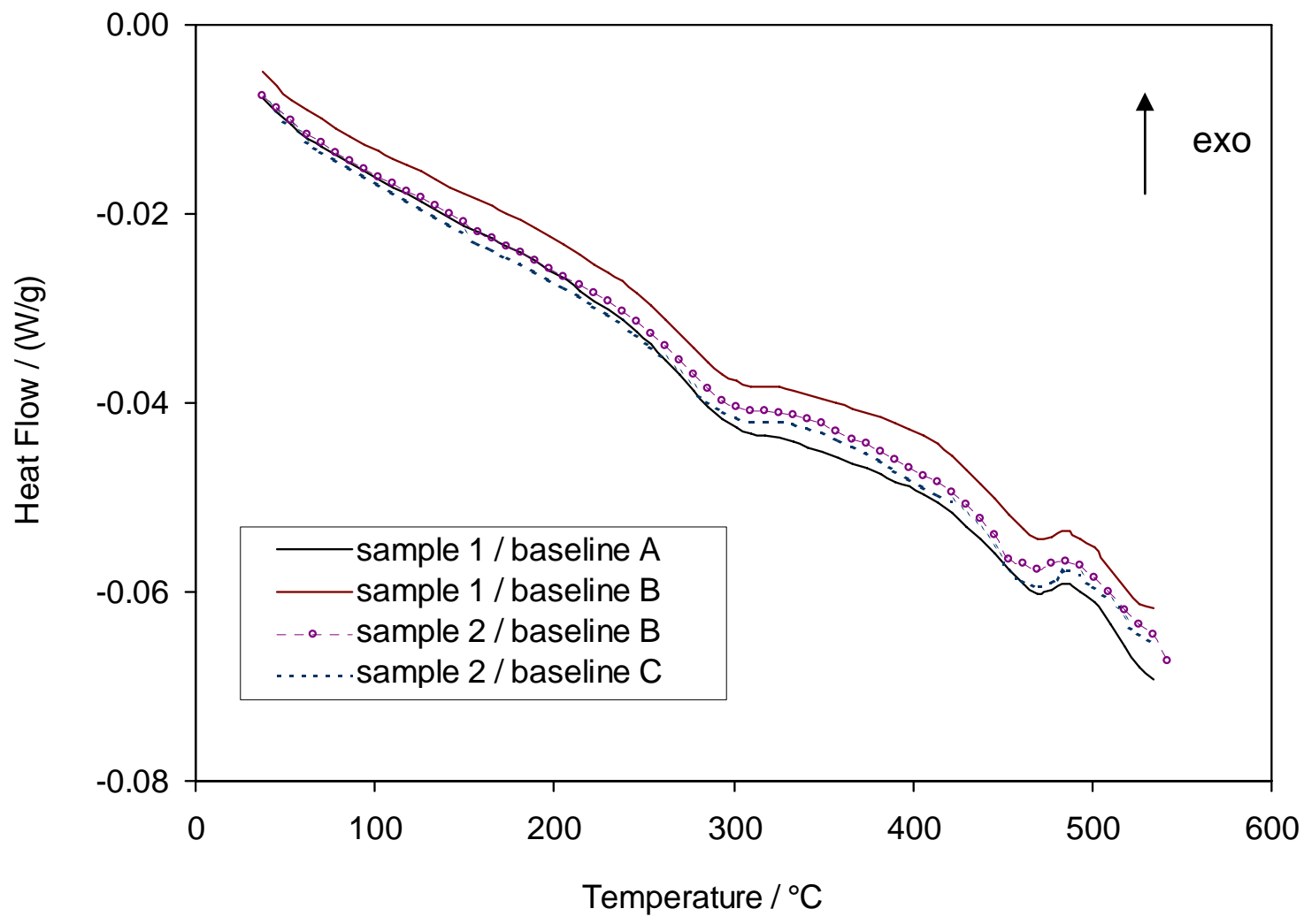

Fig. 1 Sample run minus baseline run of the Al-1.3at\%Mg-0.4at $\% \mathrm{Mn}-0.07 \mathrm{at} \% \mathrm{Cu} 10 \%$ deformation samples aged for 21 days at $170^{\circ} \mathrm{C}$. Four measurements are show, which are formed from combinations of 2 DSC runs on the alloy samples and 3 different baselines.

A similar analysis of repeatability of the DSC experiments after baseline correction and linear correction for heat capacity was performed for both alloys in the as cold-rolled condition and aged for 2,7 and 21 days at $170^{\circ} \mathrm{C}$. The variations between nominally identical experiments were similar to the ones illustrated in Fig. 2. Nevertheless, some clear and consistent differences in the thermograms were observed. As an example, Fig. 3 compares several experiments on the Al1.3at\%Mg-0.4at\%Mn-0.07at\%Cu 10\% deformation samples aged for 21 days at $170^{\circ} \mathrm{C}$, with experiments on samples of the same composition and deformation, but aged for 2 days. The latter figure clearly shows that the endothermic effect with peak at about $300^{\circ} \mathrm{C}$ has developed between 2 and 21 days ageing. Further evidence that the effect with peak at about $300^{\circ} \mathrm{C}$ is caused by extended ageing $\left(>2\right.$ days at $170^{\circ} \mathrm{C}$ ) can be obtained by subtracting a corrected DSC thermogram of an unaged or slightly aged sample from that of a sample aged for 21 days at $170^{\circ} \mathrm{C}$. We will term such a thermogram a comparative thermogram. Such a comparative thermogram for a sample aged 21 days is presented in Fig. 4, and compared in the same figure with two comparative thermograms for the same alloy aged 7 days at $170^{\circ} \mathrm{C}$, using two different samples of the aged alloy, and a comparative thermogram for the same alloy aged 2 days at $170^{\circ} \mathrm{C}$. The curves of $\mathrm{Al}-$ 1.3at\%Mg-0.4at\%Mn-0.07at\%Cu samples aged for 7 and 21 days consistently show the endothermic effect with peak at about $300^{\circ} \mathrm{C}$ as illustrated in Fig. 4. This confirms that this effect is caused by extended ageing ( $>2$ days at $170^{\circ} \mathrm{C}$ ). This figure further shows that for 2 days ageing an 
endothermic peak at about $230^{\circ} \mathrm{C}$ is present, whilst the effect peaking at $300^{\circ} \mathrm{C}$ is absent. Fig. 4 also shows considerable variations in the heat effects beyond $320^{\circ} \mathrm{C}$, even though ageing at $170^{\circ} \mathrm{C}$ is unlikely to affect this part of the thermograms, and even for samples that are nominally identical. However none of the curves show any clear heat effect with a local minimum or maximum in the heat flow in this temperature range. Thus we must conclude that we can not reliably determine the thermograms beyond $320^{\circ} \mathrm{C}$. In Fig. 4, the endothermic effect with a peak at $460^{\circ} \mathrm{C}$, which was clearly distinguishable in Fig. 2 and Fig. 3, has disappeared. This indicates that ageing at $170^{\circ} \mathrm{C}$ has not influenced the reaction(s) responsible for this effect.

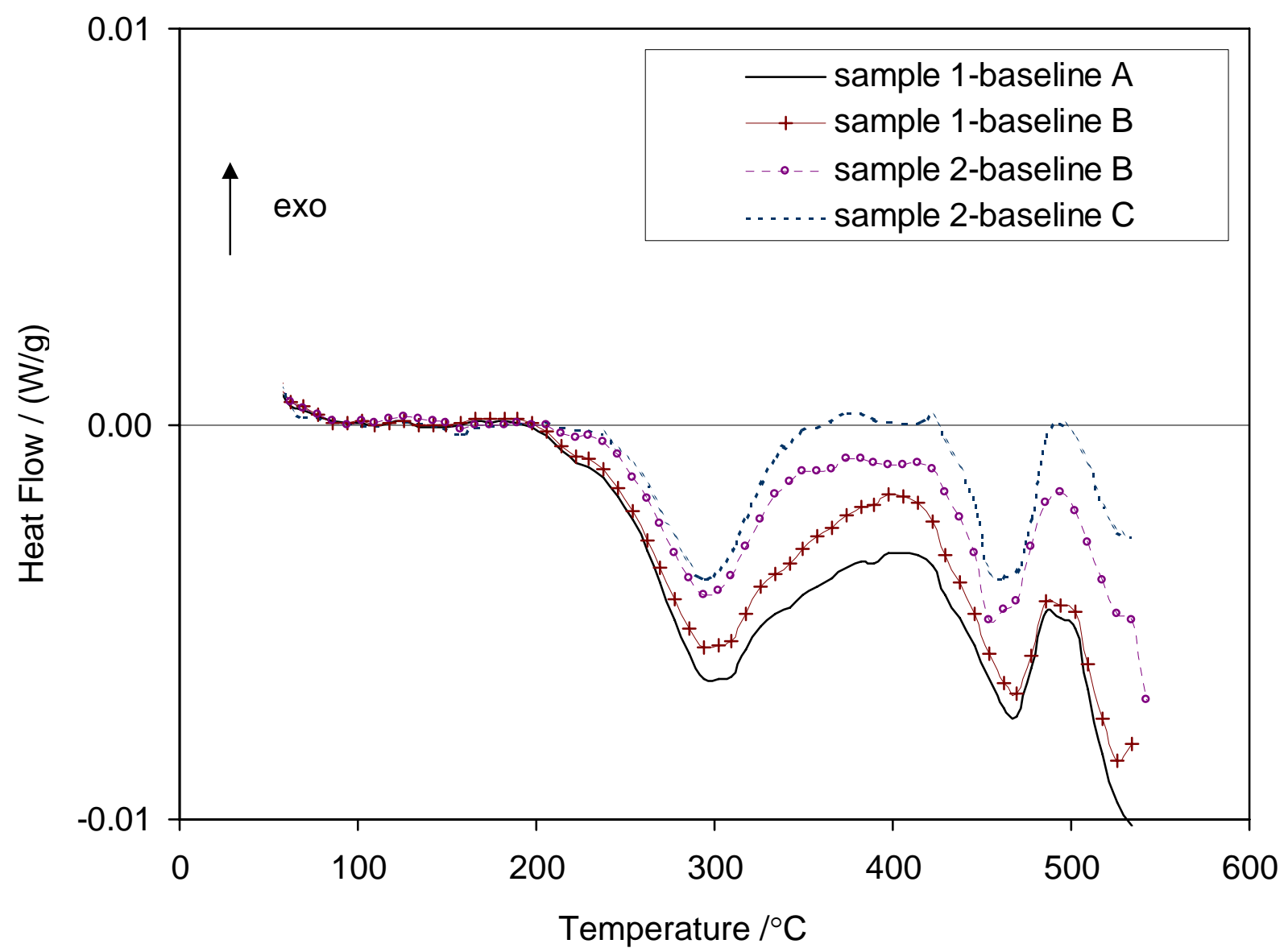

Fig. 2 Thermograms corrected for baseline run and heat capacity (linear function) of the Al1.3at\%Mg-0.4at\%Mn-0.07at\%Cu 10\% deformation samples aged for 21 days at $170^{\circ} \mathrm{C}$. Four measurements are shown, which are formed by 2 samples and 2 baselines for each sample.

The above analysis reveals the experimental limitations encountered when analysing $\mathrm{Al}$ alloys in which very small heat effects occur. However, it is equally clear that, through the present careful analysis and comparison of repeated experiments, certain small heat effects can be shown to be clearly reproducible, and suitable for analysis. The strongest reproducible effects caused by ageing are the endothermic effect with peak at $300^{\circ} \mathrm{C}$ in samples aged for 7 and 21 days and the effect at about $230^{\circ} \mathrm{C}$ in samples aged for 2 days. We have measured the heat contents of the endothermic effect with peak at $300^{\circ} \mathrm{C}$ in our $\mathrm{Al}-1.3 \mathrm{Mg}-0.4 \mathrm{Mn}-0.07 \mathrm{Cu}$ and $\mathrm{Al}-1.3 \mathrm{Mg}-0.4 \mathrm{Mn}$ samples with 3 
levels of cold deformation and 4 ageing conditions. We found that for the $\mathrm{Cu}$ free alloy in both aged and as cold worked conditions no significant heat effect could be observed. Also the as cold worked Al-1.3Mg-0.4Mn-0.07Cu showed no significant heat effect. In the aged Al-1.3Mg-0.4Mn0.07Cu samples we could detect this endothermic heat effect and the magnitude is presented in Fig. 5. This figure shows a uniform increase of dissolution energies with ageing time, indicating the amount of precipitate increases with ageing time. The difference between our two alloys is in line with work on $\mathrm{Al}-3 \mathrm{at} \% \mathrm{Mg}-0.1 \mathrm{at} \% \mathrm{Mn}-\mathrm{xCu}$ alloys which shows precipitation hardening for $\mathrm{x}>0.08 \mathrm{at} \%$ and no precipitation hardening for $\mathrm{x}=0$ [20].

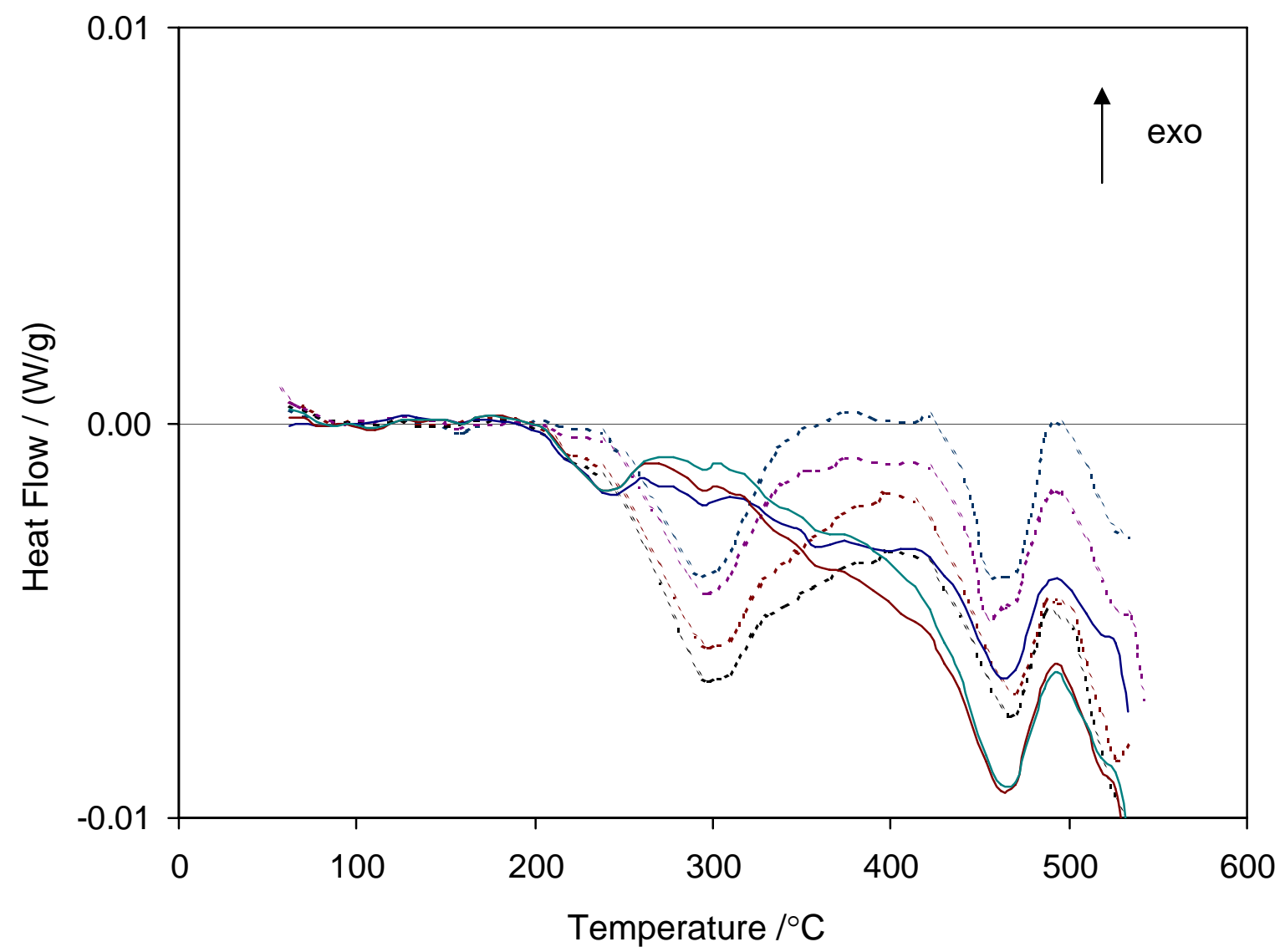

Fig. 3 Thermograms corrected for baseline run and heat capacity (linear function) of the Al1.3at\%Mg-0.4at\%Mn-0.07at\%Cu 10\% deformation samples aged for 2 days (solid lines) and for 21 days (dotted lines) at $170^{\circ} \mathrm{C}$.

\section{$4 \quad$ Discussion.}

In order to aid modelling and understanding of the DSC data of the present alloys, the solvi of S phase and $\mathrm{Cu}-\mathrm{Mg}$ clusters in low $\mathrm{Cu} \mathrm{Al}-\mathrm{Mg}-\mathrm{Mn}-\mathrm{Cu}$ alloys is modelled using a regular solution model as presented before [23,24]. It is noted that in thermodynamic sense there is no difference between $S$ phase and the phase that is usually indicated as $S^{\prime}$ as both have the same structure. The method assumes that solid solubility of elements $A$ and $B, c_{A}, c_{B}$, for phases of the type $M_{m} A_{a} B_{b}$ ( $\mathrm{M}$ is the main constituent of the alloy), is given by [25]: 
$\left(C_{A}\right)^{a}\left(C_{B}\right)^{b=} c_{1} \exp [-\Delta H / R T]$

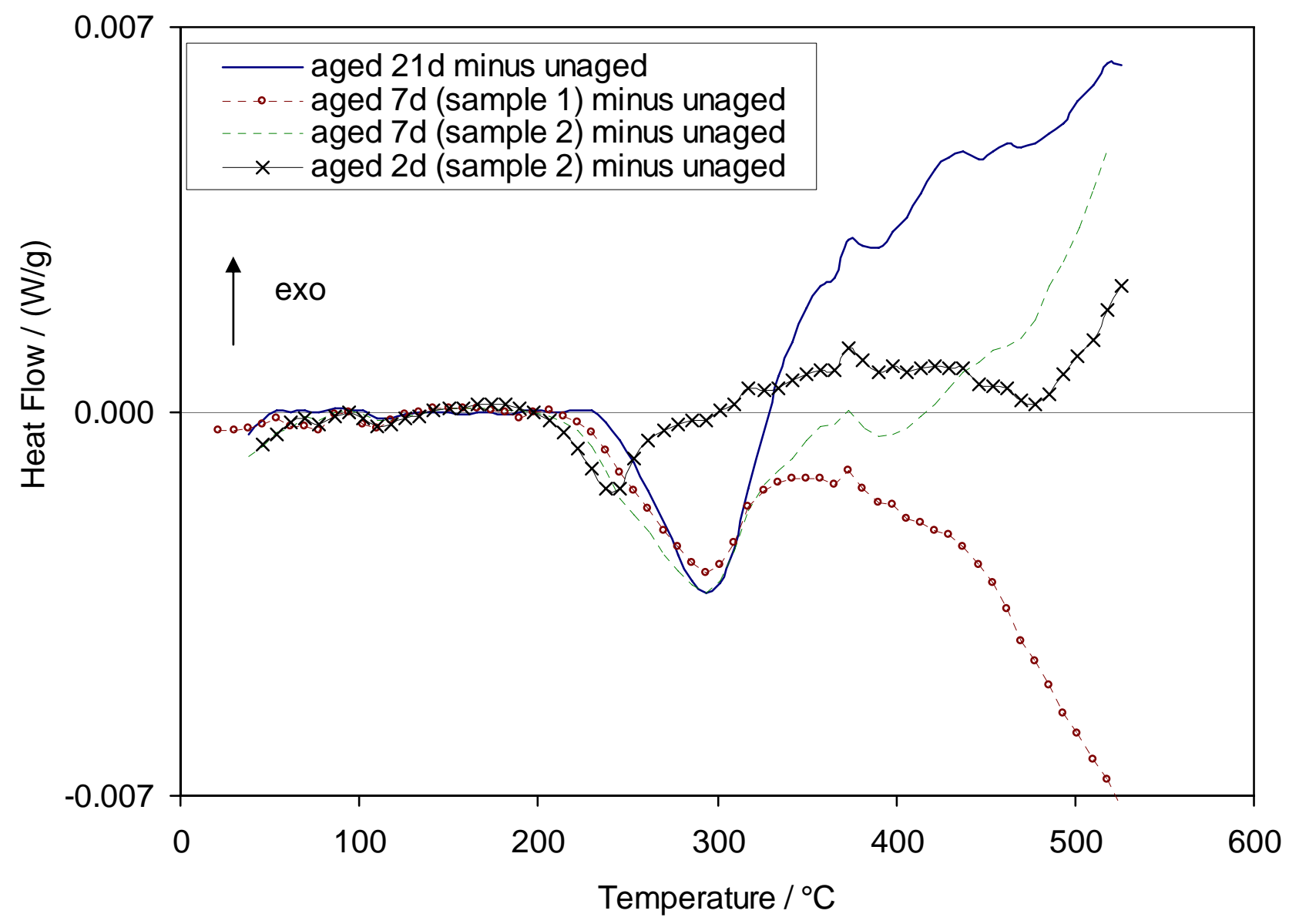

Fig. 4 Difference of a thermogram of the Al-1.3at\%Mg-0.4at\%Mn-0.07at\%Cu 10\% deformation samples aged for 21 days (dotted lines) at $170^{\circ} \mathrm{C}$ and an unaged sample of the same alloy, compared with two measurements of the difference of a thermogram of the $\mathrm{Al}-1.3 \mathrm{at} \% \mathrm{Mg}$ 0.4at\%Mn-0.07at\%Cu 10\% deformation samples aged for 7 days (dotted lines) at $170^{\circ} \mathrm{C}$ and an unaged sample of the same alloy.

where $\Delta H$ is the enthalpy of formation of one 'molecule' of $\mathrm{M}_{\mathrm{m}} \mathrm{A}_{\mathrm{a}} \mathrm{B}_{\mathrm{b}}, R$ the gas constant, $c_{1}$ is a (pre-exponential) constant. $\Delta H$ and $c_{1}$ are determined by fitting to data on $\mathrm{S}$ phase dissolution in $\mathrm{Al}$ Mg-Cu alloys as obtained from DSC experiments [23,26] and for the clusters by data on cluster strengthening Al-Cu-Mg alloys from [27]. A graph for the solvus of S phase is given in Fig. 6. This figure indicates that $\mathrm{S}$ phase can form at $170^{\circ} \mathrm{C}$ for alloys with very low copper content. In fact, for our alloys and other typical canstock alloys with about $1 \mathrm{at} \% \mathrm{Mg}$, the Cu solubility is predicted to be less than $0.001 \mathrm{at} \%$ at $170^{\circ} \mathrm{C}$ and hence practically all copper that is dissolved after solution treatment can, in principle, precipitate to form $\mathrm{S}$ phase. One factor that could limit the amount of $\mathrm{Cu}$ available for $\mathrm{S}$ phase formation is the presence of $\mathrm{Fe}$, which can combine in some alloys with $\mathrm{Cu}$ to form phases of the type $\mathrm{Al}_{7} \mathrm{Cu}_{2} \mathrm{Fe}$. However, literature indicates that for the present alloys and other typical canstock alloys with $\mathrm{Cu}$ contents below 0.1 at\% no $\mathrm{Al}-\mathrm{Cu}-\mathrm{Fe}$ phases will form $[28,29,30]$, and hence all $\mathrm{Cu}$ should be available for $\mathrm{S}$ phase formation. Similar calculations for Cu-Mg clusters 
indicate that the metastable solvus is well in excess of $170^{\circ} \mathrm{C}$ and hence these clusters should not form in the present ageing treatments.

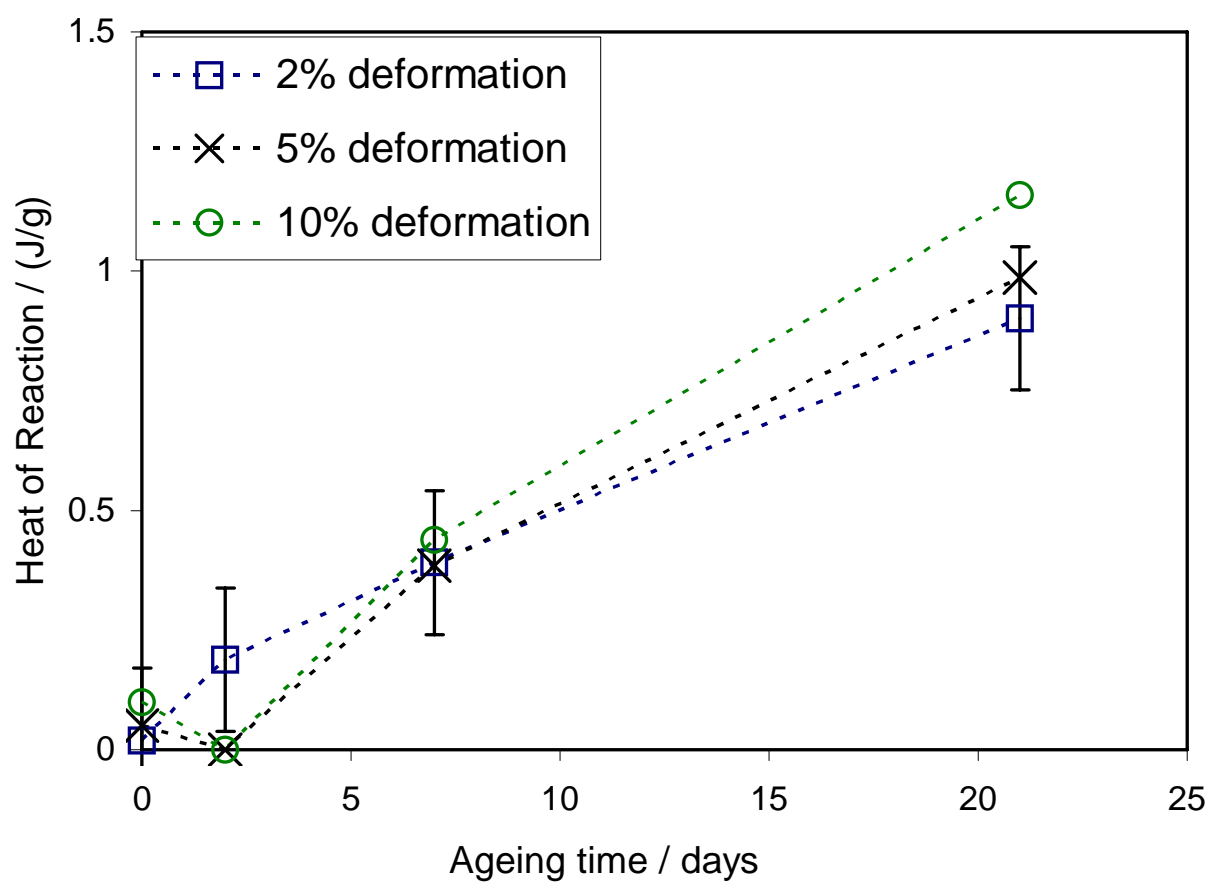

Fig. 5 Heat content of the exothermic effect with peak at $300^{\circ} \mathrm{C}$ for the aged $\mathrm{Al}-1.3 \mathrm{at} \% \mathrm{Mg}-$ 0.4 at $\% \mathrm{Mn}-0.07 \mathrm{at} \% \mathrm{Cu}$ with 3 levels of cold deformation.

Fig. 6 further shows that for the present alloy with 0.07at\% $\mathrm{Cu}$ and $1.3 \mathrm{at} \% \mathrm{Mg}, \mathrm{S}$ phase dissolution during heating should be completed at about $310^{\circ} \mathrm{C}$. This corresponds very well with the temperature where the endothermic effect that appears in samples aged for 7 and 21 days is nearly completed, and hence the temperature range of this effect is consistent with $\mathrm{S}$ phase dissolution. The latter indicates that the phase precipitating in our $\mathrm{Al}-1.3 \mathrm{Mg}-0.4 \mathrm{Mn}-0.07 \mathrm{Cu}$ alloy on extended ageing at $170^{\circ} \mathrm{C}$ is either $\mathrm{S}$ phase or a $\mathrm{Cu}$ containing phase that has a solvus very similar to that of $\mathrm{S}$ phase. As $\mathrm{S}$ phase has been detected in aged $\mathrm{Al}-\mathrm{Mg}$-Cu alloys with $\mathrm{Cu}$ contents similar to the one in our $\mathrm{Al}-1.3 \mathrm{Mg}-0.4 \mathrm{Mn}-0.07 \mathrm{Cu}$ alloy [16], and no distinct dissolution effect was detected in this temperature range for the $\mathrm{Cu}$-free alloy, it is very likely that the exothermic effect is due to dissolution of S phase. Conversely, the phase/structure that is dissolving in the endothermic effect at the lower temperature of $230^{\circ} \mathrm{C}$ in the samples aged 2 days at $170^{\circ} \mathrm{C}$ is clearly a phase/structure that is less stable than $\mathrm{S}$ phase. As noted in the previous paragraph, $\mathrm{Cu}-\mathrm{Mg}$ clusters are expected to not be stable at $170^{\circ} \mathrm{C}$ in our $\mathrm{Al}-1.3 \mathrm{Mg}-0.4 \mathrm{Mn}-0.07 \mathrm{Cu}$ alloy, and hence the phase/structure that is dissolving around $230^{\circ} \mathrm{C}$ can not be $\mathrm{Cu}-\mathrm{Mg}$ clusters. Instead, this phase/structure may be a structure termed GPBII zone or ordered zone [16] or a phase termed S" which has been claimed to be present for several $\mathrm{Al}-\mathrm{Mg}-\mathrm{Cu}$ alloys with low $\mathrm{Cu}: \mathrm{Mg}$ ratio [31], for instance in an $\mathrm{Al}-3.3 \mathrm{at} \% \mathrm{Mg}-0.18 \mathrm{at} \% \mathrm{Cu}$ alloy aged for 4 hours at $180^{\circ} \mathrm{C}$ in which the $\mathrm{S}$ " phase was detected by high resolution electron microscopy [32]. In fact, a structure for a GPBII/S" phase (orthorhombic with lattice parameters $0.4,0.4$ and $1.6 \mathrm{~nm}$ ) was recently proposed by our group [31], and it was shown that diffraction and 
HREM data on alloys with $\mathrm{Cu}: \mathrm{Mg}$ ratio close to 1 is consistent with this structure. Further investigations would be needed to confirm the presence of these structures/phases in the present low $\mathrm{Cu}$ alloys and to verify the structure of GPBII/S".

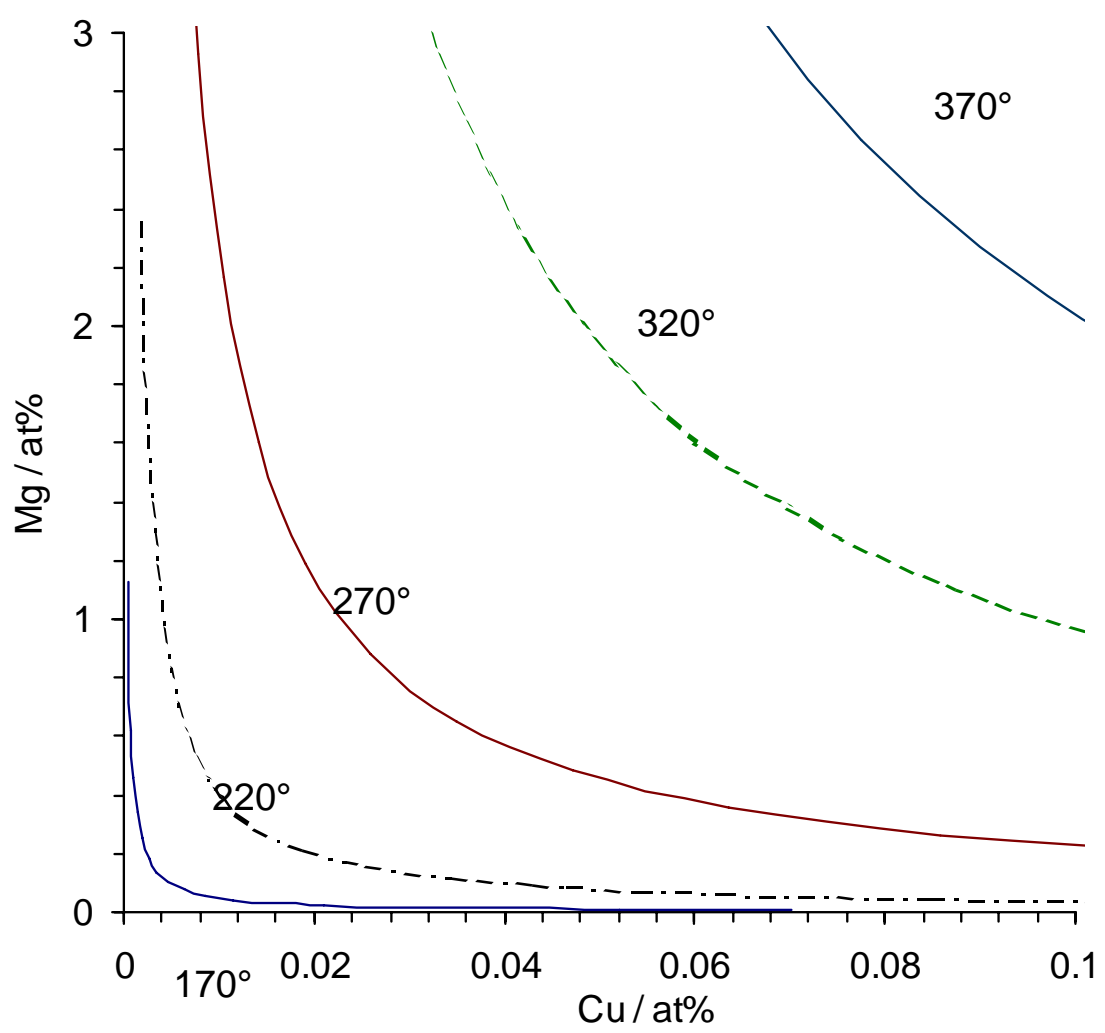

Fig. 6 Solvi of S phase at 170, 220, 270, 320 and $370^{\circ} \mathrm{C}$.

The 10\% deformed samples aged for 21 days have a somewhat higher heat content for the S phase dissolution effect as compared to the samples with lower deformation (see Fig. 5). This deviation suggests that the high deformation levels (higher than 5\%) enhance $S$ phase formation rates after ageing for about 1 week. This could be due to the increased level of heterogeneous nucleation sites (such as dislocations) available for $\mathrm{S}$ phase formation or to enhanced diffusion of atoms along dislocations.

It is finally noted that the heat effects at temperatures in excess of $320^{\circ} \mathrm{C}$ including the endothermic peak at about $470^{\circ} \mathrm{C}$ are likely to be caused by the precipitation and subsequent dissolution of $\mathrm{Mn}$ containing phases (see e.g. [30]). The baseline variability and drift as illustrated in Figs 2-4 proved too severe to provide a meaningful analysis of these effects.

\section{$5 \quad$ Conclusions}

DSC has been employed to detect and analyse precipitation reactions in an Al-1.3Mg-0.4Mn and an $\mathrm{Al}-1.3 \mathrm{Mg}-0.4 \mathrm{Mn}-0.07 \mathrm{Cu}$ alloy in which very small amounts of precipitate, less than 0.3 at $\%$, are 
expected to form. It is shown that due to the very small heat effects, baseline instability and drift significantly interfere with the measurements, and multiple experiments and careful baseline correction are needed to detect and demonstrate reproducibility of effects. In the Cu containing alloy, ageing at $170^{\circ} \mathrm{C}$ causes the appearance of two endothermic effects: for 2 days ageing a small dissolution effect at about $230^{\circ} \mathrm{C}$ appears, whilst for 7 and 21 days ageing a dissolution peak at about $300^{\circ} \mathrm{C}$ appears. The temperature range of the latter is consistent with $\mathrm{S}$ phase dissolution, whilst the former is thought to be due to a phase/structure that is less stable than $\mathrm{S}$ phase.

\section{Acknowledgements}

The authors would like to thank Alcan International for providing the alloys and support for this work, and thank Drs G. Mahon, M. Hao and S. Court for their technical input.

\section{References}

[1] M.J. Starink, Int. Mater. Rev., 2004, in press

[2] M.J. Starink and J. Yan, Proc. of 1st International Symp. on Metallurgical Modeling for Al Alloys, ASM Materials Solutions 2003, October 12-15, 2003, Pittsburgh, PA, USA, in press

[3] M.J. Starink, N. Gao, L. Davin, J. Yan, A. Cerezo, Acta Mater., submitted

[4] M.J. Starink and A.-M. Zahra, Thermochim. Acta 292 (1997) 159

[5] M.J. Starink and S.C. Wang, Acta Mater. 51 (2003) 5131

[6] A. Deschamps, A. Bigot, F. Livet, P. Auger, Y. Brechet, D. Blavette, Philosoph. Mag. 81 (2001) 2391.

[7] M.J. Starink, P. Wang, I. Sinclair, P.J. Gregson, Acta Mater. 47 (1999) 3841.

[8] M.J. Starink, P. Wang, I. Sinclair, P.J. Gregson, Acta Mater. 47 (1999) 3855.

[9] M.J. Starink and A.-M. Zahra, Phil. Mag. A 76 (1997) 701.

[10] P. Ratchev, B. Verlinden, P. De Smet and P. Van Houtte, Scripta Mater. 35 (1998) 1195

[11] P. Ratchev, B. Verlinden, P. De Smet and P. Van Houtte, Acta Mater. 46 (1998) 3523

[12] J.M. Howe, Metall. Trans. A 17A (1986) 593.

[13] S.P. Ringer, K. Hono, I.J. Polmear, and T. Sakurai, Appl. Surf. Sci., 94-5, (1996) 253.

[14] A.K. Gupta, P. Gaunt, and M.C. Chaturvedi, Philos. Mag. A, 55, (1987) 375.

[15] B. Verlinden and A.-M. Zahra, Mater. Sci. Forum 426 (2003) 423

[16] P.I. Gouma, D.J. Lloyd and M.J. Mills, Mater. Sci. Eng. A 319-321 (2001) 439

[17] Z. Zhu and M.J. Starink, Proc. of $9^{\text {th }}$ PG Conf. in Eng. Mater., University of Southampton, Southampton, 2003

[18] G.B. Burger, A.K. Gupta, P.W. Jeffrey and D.J. Lloyd, Mater. Charact. 35 (1995) 23

[19] M.C. Carroll, P.I. Gouma, G.S. Daehn and M.J. Mills, Mater. Sci. Eng. A 319-321 (2001) 425

[20] S.A. Court, K.P. Hicklin and D.J. Lloyd, Mater. Sci. Forum, 396-402 (2002) 1031

[21] C. Michaelsen, K. Barmak and T.P. Weihs, Phys. D 30 (1997) 3167

[22] C. Y. Zahra and A.-M. Zahra, Thermochim. Acta 276 (1996) 161

[23] M.J. Starink and P.J. Gregson, Scr. Metall. Mater. 33 (1995) 893.

[24] M.J. Starink and P.J. Gregson, Mater. Sci. Forum 217-222 (1996) 673

[25] R.H. Brown and L.A. Willey, in 'Aluminium Vol. I: Properties, Physical Metallurgy and Phase Diagrams’, K. R. Van Horn, ed., 1967, ASM, Metals Park, Ohio, USA, p. 31

[26] P. Ratchev, B. Verlinden and A.-M. Zahra, Mater. Sci. Forum 331-337 (2000) 1095.

[27] R.H. Beton and E.C. Rollason, J. Inst. Metals 86 (1957-58) 77.

[28] G.J. Marshall, Mater. Sci. Forum 217-220 (1996) 19.

[29] R.G. Kamat, J. Min. Met. Mater. Soc. 48 (1996) 34.

[30] Y.J. Li and L. Arnberg, Mater. Sci. Eng. A 347 (2003) 130

[31] S.C. Wang and M.J. Starink, Proc. of EMAG2003, Sept 3-5, 2003, Oxford, UK

[32] L. Kovarik, P.I. Gouma, C. Kisielowski, S.A. Court and M.J. Mills, Mater. Sci. For. 396-4 (2002) 845 